\title{
CULTURE SECTOR IN URBAN DEVELOPMENT: RE-BUILDING COMPLETE COMMUNITIES IN THE DEVELOPED CITY
}

\author{
Harsha Munasinghe*
}

\begin{abstract}
The cities in the developed world make attempts to build complete communities. They continuously build facilities and patronize events to bring people back to the city by using the strength of the culture sector. The theme of this paper is the convergence of urban development and culture. The protection and re-use of heritage buildings and infusing cultural activities to the protected built spaces as well as building new cultural facilities and patronising cultural events have taken a significant turn in the developed world since 1980s. This paper, based on a literature survey, looks into the cities in the developed world and focuses on to the cases where the culture sector has been given a special attention. However, it is noteworthy in selecting cultural facilities and events, the city managers have prioritized attracting visitors rather than all residents. Since these activities do not necessarily represent the evolution of the city culture and have failed to congregate the sub-societies, the compartmentalization of the developed city continues.
\end{abstract}

\section{BACKGROUND}

The culture sector has become a noticeable player in urban development process since 1980s. This convergence, aimed at facilitating complete communities in the city, promotes the addition of cultural institutions such as museums, galleries, opera houses, concert halls, etc. and diverse cultural activities such as festivals, sports, etc. This cultural planning undoubtedly has been an important step towards making the city a living space (Evans, 2000). The European City of Culture Programme that primarily aims at strengthening the unique identity of each European city is the highlight of the convergence. The socio-economic resurgence of Bilbao as a result of the building cultural facilities is among the most tangible push-factors for cities to assign this new role to the culture sector. Edmonton, declaring itself as the festival city of Canada with over 40 different festivals held in a year shows another facet of this convergence. The protection, reuse, re-purpose and exhibition of tangible heritage such as buildings, city districts, etc. are also results of the new understanding of city managers who consider this convergence as overarching in rebuilding the completeness in their cities. This paper critically looks at the impact of the convergence of culture sector and urban development in building the complete community in the developed city.

The present-day globalized city is inhabited by a floating community. The city space is being continuously re-shaped by this community. The role of the culture sector, as a major player in shaping its development, is an essential area of study for those who plan to take the maximum advantage from this reshaping. This study first focuses on to the emergence of the convergence and the process of culture's elevation to play such an important role in urban matters to rebuild complete communities by recomposing the fragmented city. Then it finds those issues that have prepared the setting for its new role in the scenario of global society and possible means to improve its intended role. The point of departure of this study is an observation of side-tracking of the new role. The cities seem to have paid an undue attention on economic development deviating from facilitating the intended complete community, and as such have made attempts to create or enforce a desired identity. This culturebased image is being shaped to attract new economic benefits, hoping that the economic success may attract new societies to build complete community. This, instigating a form of gentrification, has resulted in further marginalizing some social groups and in reserving the city exclusively for a powerful minority.

The paper aims at preparing the grounds to study this conflict further as it seems to have emerged from the undue attention paid to tangible products without respecting their intangible ways of production. The complete community is defined here as the place where one could live, work and entertain. This inclusive and active community would constantly change and evolve yet professing continuity thus improving the living condition of the city. A literature survey has been used as a major research method while urban morphology

* Harsha Munasinghe, University of Moratuwa, Sri Lanka. 
is used as a method of analysis to throw light on the findings.

\section{DEFINING THE NEW ROLE}

The pre-modern city successfully tested the strength of culture sector in comprehending a desirable image to the city in order to boost its socio-economic vibrancy. It integrated spaces and events tagged with culture and entertainment to attract users and investors. Theatres, arenas, temples, pleasure gardens, etc. in Roman cities are the best examples. The more recent cities such as Helsinki, Toronto, New York, all have noted the significance of cultural activities and integrated extensive spaces for cultural facilities and events. The postmodern era understood the culture sector as a major player in urban development for its direct links with the enterprise culture, consumer society, heritage industry and tourism. Today, the place identities are shaped as a marketing tool more than a place-making tool. The new trend has also opened up innovative and unprecedented means for cities to construct images, positioning them in international and domestic competition in place-marketing. The new role of the cultural sector has been to define a unique image for each city in order to be competitive, but how far those images represent the particular city culture is not assessed. Therefore, it is difficult to comprehend this selling places is for whom and at the expense of whom! In other words, the culture sector seems to be used to construct or enforce an image that is marketable to a new society of stronger economic actors at the expense of weaker current ones. The city managers shall investigate if the societies are able to enjoy these facilities or the cities are being compartmentalized as a result of the new-found role of culture.

Some cities seem to have acquired a marketable yet positive image by using the norms of cultural planning. Their new image has a significant impact on improved urban governance and demography. Helsinki, for example, seems to have found the correct equilibrium as convergence has been appreciated by the urban society, promoting urbanization and cultural diversification. The urban society in Helsinki possesses the socio-economic strength to withstand tourism and is aware of the values of the culture sector. The domination of the value system of the so-called original society and its support to diversify the city image to be in par with other European cities is another reason for reinvigorating the city through the European City of Culture Programme. There, infusing activities to rejuvenate underutilized urban spaces and grafting new institutions, the culture sector has been used as a motor of urban economy, bringing financial benefits and positive images to the city. It shall be noted that Helsinki was one of the few cities that instituted an authority to plan and manage its City of Culture programme (Heikkinen, 2000). However, this is not the case everywhere as some cities are inhabited by societies of less buying power. There, the cultural activities seem to be used by more affluent social groups and tourists. For example in Toronto, the culturally up-scaled urban space is too expensive for many subsocieties. There are cases where the constructed images do not facilitate continuous living: for example the concept of festival city has not been attractive to the families with children in Edmonton. Athens, on the other hand, is going through economic hardships after hosting Olympics in 2004. There are many such cases where convergence did not necessarily facilitate the complete community.

The most beneficial aspect of this flagship policy is its propensity to answer the problems caused by deindustrialization in the cities, where the traditional manufacturing base collapsed thus leaving extensive urban spaces underused or unused. The re-adoption of abandoned spaces such as factories, warehouses, butcheries, rail-yards, etc. to cultural and entertainment activities has given the city a new lease of life and constructed a positive image, and more importantly brought back the city life ejected by industrialization. This rejuvenation of abandoned spaces did attract new users closely followed by new investments. The culture sector, originally conceived for this city transformation, represents evolved societies and reinterprets their activities with a new tag. It is similar to re-humanizing the post-industrial city while adding a new heritage to city's benefit (Ashworth, et.al. 2007). The aforementioned case, Bilbao and the preservation of So-Ho district in New York are among instructive examples to strengthening the city life through convergence of urban development and culture.

Discussing the need for integrating the culture sector, (Bianchini, 1991) notes that there are four types of European cities, where different circumstances demanded the convergence:

1. Declining cities; where culture is used to diversify the economy and reconstruct their image (Glasgow, Liverpool, Hamburg, Rotterdam)

2. Economically prosperous political or administrative hubs; which may be culturally less-advantaged but the culture sector is used to create a new competitiveness (Frankfurt, Munich, Stuttgart, Brussels, Strasbourg)

3. Culture capitals or centres for cultural production; where cultural policies are aimed at consolidating their position and adapting the local cultural infrastructure to changes 
in fashion, technologies and marketing styles (London, Paris, Amsterdam, Berlin, Rome)

4. Research and development cities; where sectors of economy that depend their success on cultural input is generated by nurturing creativity and talent, supporting an environment to produce innovations, and forging links between local cultural industries and advanced research (Rennes, Grenoble, Cologne, Hamburg, Milan, Barcelona).

In the first type, the culture sector has provided a solid transformative impact bringing success in terms of economics through a combine of building-based hard policy and activitybased soft methods. Most of the cities witnessed a complete grafting of the culture sector on the historic built spaces through renovation or re-purposing. The building-based policies have easily been favoured for their ability to create jobs by taking the advantage of the potential growth prospects and more tangible results. This, on the other hand, can be directly linked to the post-industrial scenario; making attempts to enlarge employment in the service sector and to offer entertainment to growing number of middle-class consumers in addition to giving a new lease of life to those abandoned spaces and city districts. The new values ascribed to spaces used for usual day-to-day activities and claiming those spaces as city's heritage has diversified city's image. The noticeable success of the culture sector as a source of economic prosperity in some cities has encouraged the others to take up such initiatives in to the central elements in their future plans. Most of those initial efforts did not focus on to the potential danger of replacing the evolved urban society, its values and activities that shaped those spaces because the city managers understood the strength of their city and its particular place in the said categories.

The next phase of development is marked by infusion of typical or standard cultural activities that are solely aimed at economic success. City managers, arguing for economic development as the development of the city, promoted this standardization that included new or renovated buildings, designed or re-purposed by globally-known architects to accommodate various museums, galleries, cinemas, theatres, etc. Some of these activities have no connection to the evolved city culture and as such do not represent the evolved city life or the cultural strength of the city. By initiating such building projects, cities have created jobs, become attractive to mobile investments and tourism. They may have strengthened the revenue base by engaging in domestic and international competitions with others. Their repositioning in the global market to catch the increasingly-mobile capital has posed both threats and challenges to place-perceptions. Yet, there is a potential danger of distancing own citizens in search of richer citizens (Zukin, 2010) notes how some communities were forced out of New York as a result of embedding the culture tag on the working class built spaces and thereby making them too expensive for those communities. The most intriguing issue is cultural value of the place is not any more emerging from the lived life but from some imported items.

North American cities reflect all four types at once in their new compositions and they are much younger than their European counterparts. They are using the culture sector to diversify the economy while networking all types of new and old functions necessarily with new meanings. In the North American city, the heritage interpretation is largely based on tangible values and built spaces are protected mostly as isolated objects exhibited for a diversifying society. The conserved space accommodates various cultural activities and entertainment. It is interpreted and expressed quantitatively for tourism. This conservation, in turn, demands the protection of built environment against tourist masses, kitsch and standardization. It is important to interpret a particular shaping of a tangible product in order to preserve its uniqueness (Munasinghe, 2003). It is also important to assess the strength of new functions in upholding the uniqueness of a heritage building and the place identity.

The use of culture sector and particularly the reinterpreted heritage to smoothen social conflicts between old residents and new immigrants, or in other words community rebuilding, is crucial in the North American city occupied by a multicultural society. However, the tourists and some immigrants become more powerful in the city and demand the city to adapt to a global-orientation as shown in the case of New York. Sustaining communities shall be designed over time, especially in those multicultural cities. It is noteworthy that such a city shall set goals in rebuilding complete communities using the culture sector and interpreting historic spaces and activities to congregate all sub-societies: new or old. The additions to the Royal Ontario Museum in Toronto, Canada has conceived an inclusive attempt to depict cultural continuity, diversifying city's landscape and making attempts to emphasize its evolution. The museum clearly exhibits the evolution of a country that was then known as 'Kanata', meaning a village or a settlement.

The strength of the culture sector in constructing a desirable image and its capacity could be used as an efficient communication device for displaying city's lively and active 
appearance. This could be manipulated in shaping the new role of culture sector- the congregator. Since the images play a significant part in determining the fortunes of cities in attracting visitors, services, entrepreneurs and new residents as well as retaining existing services and residents, selecting a vision for urban development is the most important. An image that suites or is attractive to all parties may not exist, but the culture sector in each city has its own strength in determining the most desirable image, which is found within rather than importing from a so-called successful city. The new role of the culture sector has the capacity to shape a desirable vision for urban development and as such to facilitate complete communities.

\section{REFLEXIVITY OF CULTURAL PLANNING}

The earlier discussion focused on city's promotion campaigns since 1980s, in which inclusion of cultural sector has been heavily used for urban development. This process has replaced a pattern of sporadic and short-term phases where cities had adopted a reactionary rather than an active approach to urban development. The cultural planning strategically aimed at more substantial and envisioned developments than mere problem-solving exercises. Yet, most of the extensive projects, having paid undue attention on the completion, have included a sizeable portion of showing off to exhibit the city in an imposing manner to attract various kinds of exhibitions, conventions, games or events to earn revenue. Staging these events demanded enormous efforts on infrastructure development thus turning a new chapter in city's history but not necessarily with happy endings. In some cases, the investment did not bring ample outcomes to rebuild city's economy, and sustaining its event-based economy has pushed some cities to the brink of bankruptcy. Learning from mistakes, some scaled down their investments and cleverly integrated the new developments with the needs of the living society instead of theming their city images yet aiming at users with higher spending capacity. In Toronto, housing is being added in the city along with the addition of new cultural facilities. However, the housing is mostly aimed at selected social groups: younger or older child-less executives thus leaving out many. It is on the other hand possible that these are citizens who would use the cultural facilities.

It is a fact that the nature of production in the city is changing, making a huge impact on city's landscape, their communities and more on the value systems. This re-shapes the needs of facilitating complete communities by being attractive to a diversity of social actors. In the post-industrial city, (Lash et.al, 1994) note, "What are interestingly produced are not material objects, but signs". The city managers seem to be increasingly interested in those signs, and this is why the ordinary manufacturing industry in the city is becoming a cultural product. The values ascribed with just day-to-day production such as handloom clothes, hand-woven laces, food and spaces such as small boutiques, taverns, cafes marks the new trend of commoditizing otherwise ordinary products and spaces. This is why Lash et.al (1994) find, “... it is not that commodity manufacture provides the template, and culture follows, but that cultural industries themselves provided the template". This reverse trend demands the adaptation of the community to cultural products rather than represent them. It is easier to understand this trend through the concept of reflexivity that denotes the circular relationship between cause and effect and therefore often been discussed in relation to contemporary modernity (Gay, 2009).

On the other hand, reflexivity means increasing social and individual self-monitoring. Lash (1999), citing Kant's aesthetics in The Critique of Judgment, observes that people are reflexive cognitively as well as aesthetically. As aestheticreflexivity indicates more than self-monitoring that denotes hermeneutic self-interpretation. Thus aesthetic reflexivity enables individuals to be aware of, take reflexive distance to, and to manipulate information of societal flows and signs. Interestingly, this informs the possible conflicts between city's community and cultural activities introduced to instigate urban development. It is important to note that the local community and visitors would take reflexive action based on their own aesthetic reflexivity. The displayed cultural activity or production may thus complement continuous socio-economic development in the city. If the culture sector promotes activities that are discovered from the evolved values of the community, the aesthetic reflexivity could strengthen city's efforts to build and sustain the complete community.

Aesthetic reflexivity thesis assists understanding the eroding boundary between art and everyday life: for example, yesterday's everyday life is becoming today's cultural product. Such observations have a direct impact on the future of cities with our today's usual actions may be becoming cultural products of tomorrow. The individuals who are well-placed to manipulate and benefit from new information and communication structures and who consume the informational goods have the ability to aestheticize everyday life in order to garner economic benefits are labelled as reflexivity winners by Lash (1999). The new middle class emerged in the city as a result is, branded as cultural intermediaries by (O'Connor \&Wynne, 1995). The cities try to attract them as residents or entrepreneurs since they 
are believed to process cultural citizenship that can have a profound impact on the future success of cities. It can be assumed that cities believe that these reflexivity-winners would bring success to the city in global competitions. Yet, O'Connor and Wynne (1995) argue that the cultural intermediaries are working more for the knowledge and service industries and the public sector rather than the culture and media sphere. In addition, these people possess less cultural capital than what might have been expected. On the other hand, these cultural intermediaries are not familiar with the cultural values of the place.

The cultural intermediaries seem to occupy places for a certain period of time, promoting and abandoning places after making their profits. In other words, this society is moving from place to place and fixed to one particular place. The culture sector could become the saviour of the complete community if only there is a resultant society to take over the activities, events and spaces created by those intermediaries, who do not nurture such a generation to take over. It is therefore up to the city managers to facilitate the emergence of the successive society to sustain the city life. However, the city managers seem to be heading towards a different direction- to invent more and more new cultural activities to retain the mobile intermediaries for a longer period, thus postponing the inevitable. The culture sector, if interpreted within the uniqueness of the place- or the particular understanding between society and city, has the strength to sustain this continuity that demands the absorption of local residents to the new-found cultural facilities and events. Stockholm, Graz and Helsinki have managed to continuously interpret the cultural sector instigated by the European City of Culture program but not many others.

\section{SOCIETY, CULTURE AND PLACE}

(Zukin, 1995) coined the term symbolic economy to describe how images and products are linked with the culture industry and cultural consumption, and how this link has expanded in a global scale. For cities, this entails a need for marketing, producing and selling themselves as particular representatives of certain key symbols. The idea of European City of Culture intended to promote such symbols of each city and thereby to present the diversity of Europe as a continent. Hence the cities were to find themselves in need of producing kinds of imaginative spaces that are appealing to their particular target groups. Unfortunately, all cities seem to be going after the same target group pushing symbolic economies towards typifying. Yet, (Zukin, 1995) seems to be optimistic, "What is new about the symbolic economy since the 1970 s... is its symbiosis of image and product, the scope and scale to selling images on a national and even a global level, and the role of the symbolic economy in speaking for, or representing, the city". These images and products can be London theatre, Parisian Haute Couture or even the more recent Jewish Museum in Berlin, where the products are tightly linked to a particular place and a particular history. The uniqueness of the place is resulted by the particular way of life that evolved there. Culture, as a phenomenon, has intensively place-specific characteristics thereby differentiates places from one another. The way of production, products, consumption, and as such the economy, they all are place-specific and are highly symbolic with one another. By responding to unique characters of a place, the culture sector could become the best tool for urban development that suites the place-or in other words the most sustainable development.

In this discourse of competition, the culture sector has gained a particular significance from 1970 to 1990, where "cultural strategies that initially represented the results of economic development turned into strategies aimed at stimulating economic growth" (Zukin, 1995). The rise of the culture sector in the city can be understood through the process of cultural de-differentiation, a process of postmodernity as against the process of cultural differentiation of modernization. It can be argued that the development of the culture represents two sides of the differentiation- de-differentiation analysis. Lash (1994b) notes that only in the postmodern period has the culture sphere differentiated itself from social, political and economic life and reached an independent status. At the same time, cultural de-differentiation has enabled culture to become an important element in social, political and economic lifeand vice versa social, political and economic elements have an impact on the culture sector. Hence, the cultural elements have a role to play and they, being aesthetic in character, may include reflexive and even critical components.

The usage of cultural components in city marketing has predominantly been characterized by an instrumental, technorational, economic approach. Most of the developed cities have integrated their technological development with culture sector thus seeking a balance in the approach to develop new facilities such as cyber cafes, cable libraries, digital museums, etc. In this context, making use of the culture sector is a logical extension of strategies already adapted in the $19^{\text {th }}$ century. However, the unexpected consequences and conflicts that are inherent in the cultural developments that take place in urban enclaves have not been sufficiently recognized and that they present interesting opportunities for research. The developed city, been encroached by more 
and more immigrants who often form enclaves, is the best case for this. It is important to critically assess and present alternative views to the culture marketing approach dominated by the present-day consumer society. This study is an attempt to emphasize the relationship between society, culture and place against the re-shaping of society and place to accommodate imported cultural activities.

\section{CONCLUSION: CONVERGENCE FOR COMPLETE COMMUNITY}

The process of convergence aims at selling the city to outsiders but not to its residents. One may compare selling the city to residents as selling the products to its producers, yet the city space appreciated by the convergence will improve its capacity to build complete community. The type of cultural activities could have an intriguing connection to the place, and the society may enjoy this new-found value resulted by they being defined as cultural products. On the other hand, most of the introduced activities are globally oriented marking the diversification of cultural life in the city. Turning the public opinion in favour of the strategies, images and slogans used in city promotion campaigns seem to have made residents believe in the messages, though they often wonder if they could benefit from tourism without tourists. It is important for city authorities to use the strength of its society's buying power in planning such cultural activities and new facilities.

Understanding the demands and expectations of the local population is important if the convergence to bring success, and the city authorities should find out whose city and whose culture before planning new activities. (Eisinger, 2000) notes how most cities have prioritized providing services to visitors over facilitating the needs of the local residents. The target audience is expected to be well educated and prosperous thus leaving a major segment un-persuaded as outsiders though they may have a stake in the city. Understandably, such a situation opens up room for social conflicts and crises. Conflicting parties between locals and outsiders, the better and the less well-off, city centre and suburb residents, and the like can suddenly foreshadow the scene. Drawing from the notion of conflict prospects, it is not surprising that sometimes there are attempts to construct a new identity in order to overshadow an existing place-myth that might be considered as negative or harmful. This is an issue the culture sector has to face as well because its application to city marketing and developing opens up conflicts. "Cultural politics is an ambiguous concept", notes (Jackson, 1993), "it refers to view that cultural questions aesthetics, taste and style cannot be divorced from political question of power, inequality and oppression". Such conflicts can be structurally assessed by using the concept of urban fortunes. The importance of urban growth coalitions and the key urban developers, made out of urban elites, are preoccupied with the idea of considering cities as 'growth machines'. Even if the urban elites may differ radically on many issues, it is the desire for growth that unites them. Thus elites form a growth consensus to strive for a strategy that is then carefully formulated as inevitable and an alternative for future success.

Yet, a cultural strategy, with a true interpretation of culture and particularly respecting its intangible aspects: symbols, language, norms and values, and its place-responsiveness could frame a convergence that facilitates the building of complete communities. This strategy could promote inclusiveness, diversity, accessibility and choices to encourage a complete community. Furthermore, it could alleviate urban conflicts that are caused by the juxtaposition of exchangevalue and use-value and the relationship to them by different urban actors who may take the advantage of the rising land and property values. Such interests are opposed by local residents whose interest is to emphasize use-value of the living environment. The strength lies in the right understanding of the intangible values of culture.

It is noteworthy that the convergence of urban development and the culture sector has several areas open for new debates on the city and its management. Various problems seem to emerge: Whose city? Whose culture? Who should be given priority? For whom by whom and who is to benefit? This paper's attempt has been to bring these questions to a new forum through a literature review to prepare the grounds for cities to find their own answers. 


\section{References}

Ashworth G.J, Brian Graham and J.E. Turnbridge (2007) Pluralising Pasts: Heritage, Identity and Place in Multicultural Societies London: Pluto Press

Connor, O., Justin \& Wynne, D. (1995) City Culture \& the New Cultural Intermediaries, Parts 1-5, Manchester Institute for Popular Culture, Manchester Metropolitan University, http.//darion.mmu,ac,uk//h\&ss/mipc/citycul1.htm, dated 4.9.1997

Daniel, G. (2009) Reflexivity and Urban Economics, London: Palgrave McMillan

Evans, G. (2000) Cultural Planning London: Routledge

Franco ${ }_{*}$ B. (1991) Cultural Policy and Urban Development, the Experience of Western European Cities, Paper presented at the 8 th Urban Change and Conflict Conference at Lancaster University, cited in Timo Cantell (2000) 'The Convergence of the Culture Sector and Urban Development', Yhteiskuntasuunnitelu 3, Helsinki: Helsinki University of Technology pp. $41-53$

Harsha, M. (2003) 'Disinheriting the Inheritance: Conservation of World Heritage Cities and Heritage Proclaiming', Built Environment Sri Lanka 3 (2) Colombo February 2003: pp. 49-58

Heikkinen, T. (2000) 'In from the margin: the city of culture 2000 and image transformation in Helsinki', International Journal of Cultural Policy 6, 200-218

Peter, J. (1993) 'Towards a Cultural Politics of Consumption in John Bird, Barry Curtis', Tim Putnam, George Robertson and Lisa Tickner (eds.) Mapping Futures: Local Cultures, Global Change, London: Routledge 207-228

Scott, L. (1990) Sociology of Postmodernism, London: Routledge

Scott, L. and Urray, J. (1994) Economics and Signs and Space: London, Sage: London

Sharon, Z. (1995) The Culture of Cities, Oxford: Blackwell

Sharon, Z. (2010) Naked City: The death and life of authentic urban place, New York: Oxford University Press 